\title{
Generating a vision for smart sustainable cities of the future: a scholarly backcasting approach
}

\author{
Simon Elias Bibri ${ }^{1,2^{*}}$ and John Krogstie ${ }^{1}$
}

\begin{abstract}
Sustainable cities have been the leading global paradigm of urbanism. Undoubtedly, sustainable development has, since its widespread diffusion in the early 1990s, positively influenced city planning and development. This pertains to the immense opportunities that have been explored and the enormous benefits that have been realized in relation to sustainable urban forms, especially compact cities and eco-cities. However, such forms are still associated with a number of problems, issues, and challenges. This mainly involves the question of how they should be monitored, understood, analyzed, and planned to improve, advance, and maintain their contribution to sustainability and thus to overcome the kind of wicked problems, unsettled issues, and complex challenges they embody. This in turn brings us to the current question related to the weak connection between and the extreme fragmentation of sustainable cities and smart cities as approaches and landscapes, respectively, despite the proven role of advanced ICT, coupled with the untapped potential of big data technology and its novel applications, in supporting sustainable cities as to enhancing and optimizing their performance under what is labeled "smart sustainable cities." In this respect, there has recently been a conscious push for sustainable cities to become smart and thus more sustainable by particularly embracing what big data technology and its novel applications has to offer in the hopes of reaching the optimal level of sustainability. In the meantime, we are in the midst of an expansion of time horizons in city planning and development. In this context, sustainable cities across the globe have adopted ambitious smart goals that extend far into the future. Essentially, there are multiple visions of, and pathways to achieving, smart sustainable cities based on how they can be conceptualized and operationalized. The aim of this paper is to generate a vision for smart sustainable cities of the future by answering the 6 guiding questions for step 3 of the futures study being conducted. This study aims to analyze, investigate, and develop a novel model for smart sustainable cities of the future using backcasting as a scholarly approach. It involves a series of papers of which this paper is the second one, following the earlier papers with steps 1 and 2. Visionary images of a long-term future can stimulate an accelerated movement towards achieving the long-term goals of sustainability. The proposed model is believed to be the first of its kind and thus has not been, to the best of one's knowledge, produced, nor is it being currently investigated, elsewhere.
\end{abstract}

Keywords: Smart sustainable cities, Sustainable cities, Smart cities, Compact cities, Eco-cities, Data-driven cities, Big data computing and the underpinning technologies, Future vision, Backcasting, Futures studies

\footnotetext{
* Correspondence: simoe@ntnu.no

${ }^{1}$ Department of Computer Science, Norwegian University of Science and

Technology (NTNU), Sem Saelands veie 9, NO-7491 Trondheim, Norway

${ }^{2}$ Department of Architecture and Planning, Alfred Getz vei 3, Sentralbygg 1,

5th floor, NO-7491 Trondheim, Norway
} 


\section{Introduction}

Contemporary cities have a pivotal role in strategic sustainable development; therefore, they have gained a central position in operationalizing this notion and applying this discourse. This is clearly reflected in the Sustainable Development Goal 11 (SGD 11) of the United Nations' 2030 Agenda, which seek to make cities more sustainable, resilient, inclusive, and safe [73]. Sustainable cities have long been the leading global paradigm of urbanism $[19,74,77-79]$ for more than three decades or so. The subject of "sustainable cities" remains endlessly fascinating and enticing, as there are numerous actors involved in the academic and practical aspects of the endeavor, including engineers and architects, green technologists, built and natural environment specialists, and environmental and social scientists, and, more recently, computer scientists, data scientists, and urban scientists. All these actors are undertaking research and developing strategies and programs to tackle the challenging elements of sustainable urbanism. This adds to the work of policymakers and political decision-makers in terms of formulating and implementing regulatory policies and devising and applying political mechanisms and governance arrangements to promote and spur innovation and monitor and maintain progress in sustainable cities.

Since its widespread diffusion in the early 1990s, sustainable development has had significant positive impacts on the planning and development of cities in terms of the different dimensions of sustainability. It has also revived the discussion about the form of cities [40]. In this regard, it has inspired a whole generation of urban scholars and practitioners into a quest for the immense opportunities and fascinating possibilities that could be enabled and created by, and the enormous benefits that could be realized from, the planning and development of sustainable urban forms (especially compact cities and eco-cities), That is to say, forms for human settlements that can meet the required level of sustainability and enable the built environment to function in a constructive way. This can be accomplished through continuously improving their contribution to the goals of sustainable development in terms of reducing material use, lowering energy consumption, mitigating pollution, and minimizing waste, as well as in terms of improving equity, inclusion, the quality of life, and well-being.

However, new circumstances require new responses. This pertains to the spread of urbanization and the rise of ICT and how they are drastically changing sustainable urbanism. The transformative force of urbanization and ICT and the role that cities can play have far-reaching implications. By all indicators, the urban world will become largely technologized and computerized within just a few decades, and ICT as an enabling, integrative, and constitutive technology of the twenty-first century will accordingly be instrumental, if not determining, in addressing many of the conundrums posed, the issues raised, and the challenges presented by urbanization. It is therefore of strategic value to start directing the use of emerging ICT into understanding and proactively mitigating the potential effects of urbanization, with the primary aim of tackling the many intractable and wicked problems involved in urban operational functioning, management, planning, development, and governance, especially in the context of sustainability. Indeed, the rapid urbanization of the world poses significant and unprecedented challenges associated with sustainability (e.g., [26, 31, 34]) due to the issues engendered by urban growth. In short, the multidimensional effects of unsustainability are most likely to exacerbate with urbanization. Urban growth will jeopardize the sustainability of cities [53]. Therefore, ICT has come to the fore and become of crucial importance for containing the effects of urbanization and facing the challenges of sustainability, including in the context of sustainable cities which are striving to improve, advance, and maintain their contribution to the goals of sustainable development. The use of advanced ICT in sustainable cities constitutes an effective approach to decoupling the health of the city and the quality of life of citizens from the energy and material consumption and concomitant environmental risks associated with urban operations, functions, services, strategies, and policies [13].

Smart sustainable cities as an integrated and holistic approach to urbanism represent an instance of sustainable urban planning and development, a strategic approach to achieving the long-term goals of urban sustainability-with support of advanced technologies and their novel applications. Accordingly, achieving the status of smart sustainable cities epitomizes an instance of urban sustainability. This notion refers to a desired (normative) state in which a city strives to retain a balance of the socio-ecological systems through adopting and executing sustainable development strategies as a desired (normative) trajectory [19]. This balance entails enhancing the physical, environmental, social, and economic systems of the city in line with sustainability over the long run-given their interdependence, synergy, and equal importance. This long-term strategic goal requires, as noted by [7], p. 601), "fostering linkages between scientific research, technological innovations, institutional practices, and policy design and planning in relevance to sustainability. It also requires a long-term vision, a trans-disciplinary approach, and a system-oriented perspective on addressing environmental, economic, social, and physical issues." All these requirements are at the core of backcasting as a scholarly and planning approach to futures studies. This approach facilitates and contributes to the development, implementation, evaluation, 
and improvement of models for smart sustainable cities, with a particular focus on practical interventions for integrating and improving urban systems and coordinating and coupling urban domains using cutting-edge technologies in line with the vision of sustainability. One of the most appealing strands of research in the domain of smart sustainable urbanism is that which is concerned with futures studies. The relevance and rationale behind futures research approach are linked to the strategic planning and development associated with long-term sustainability endeavors, initiatives, or solutions. And backcasting is well suited to any multifaceted kind of planning and development process (e.g., [38]), as well as to dealing with urban sustainability problems and challenges [19, 23, 29, 52, 59].

The aim of this paper is to generate a vision for smart sustainable cities of the future by answering the 6 guiding questions for step 3 of the futures study being conducted, namely:

- What are the terms of reference for the future vision?

- How does the future sustainable socio-technical system and need fulfillment look like?

- How is the future vision different from the existing socio-technical systems?

- What is the rationale for developing the future vision?

- Which sustainability problems, issues, and challenges have been dealt with by meeting the stated objectives and thus achieving the specified goals?

- Which advanced technologies and their novel applications have been used in the future vision?

This futures study aims to analyze, investigate, and develop a novel model for smart sustainable cities of the future using backcasting as a scholarly approach. It consists of 6 steps in total and a number of guiding questions for each step to answer. Accordingly, it involves a series of papers of which this paper is the second one, following the earlier papers with steps 1 and 2: strategic problem orientation [19]. This paper as a sequel leads through the whole of the backcasting study: step 4 with 2 papers, step 5 with 1 paper, and step 6 with 1 paper. All in all, as this is an extensive scholarly project involving description, investigation, synthesis, design, analysis, and compilation, it is deemed more appropriate to divide it into a series of papers.

The remainder of this paper is structured as follows. Section 2 provides a background of the futures study, including a review of the area being researched, the issue of the current situation, and studies and relevant history on the issue. Section 3 focuses on the backcasting methodology, with an emphasis on step 3. Section 4 delves into step 3 of the futures study by answering the 6 guiding questions in more detail following the applied backcasting approach. This paper ends, in Section 5, with discussion and conclusion.

\section{Background of the futures study}

Sustainable cities are associated with a number of problems, issues, and challenges (i.e., deficiencies, Limitations difficulties, fallacies, and uncertainties) when it comes to their management, planning, design, development, and governance in the context of sustainability (e.g., $[16,17,19,27,28,54])$. This mainly involves the question of how sustainable urban forms should be monitored, understood, and analyzed in order to be effectively planned, designed, developed, managed, and governed in terms of enhancing and maintaining their sustainability performance [13]. The underlying argument is that more innovative solutions and sophisticated approaches are needed to overcome the kind of wicked problems, unsettled issues, and complex challenges pertaining to sustainable urban forms. This brings us to the current question related to the weak connection of and extreme fragmentation between sustainable cities and smart cities as approaches and landscapes, respectively (e.g., [3, 7, 13, $16,19,20,49])$, despite the great potential of advanced ICT for, and its proven role in, supporting sustainable cities in improving their performance under what is labeled "smart sustainable cities" (e.g., see, $[7,8,17,49,68])$. In particular, tremendous opportunities are available for utilizing big data computing and the underpinning technologies and their novel applications in sustainable cities to improve, advance, and maintain their contribution to the goals of sustainable development. The main strength of the big data technology is the high influence it will have on many facets of smart sustainable cities and their citizens' lives (see, e.g., $[2-4,6,8,13,58,71]$ ).

In light of the above, recent research endeavors have started to focus on smartening up sustainable cities through enhancing and optimizing their operational functioning, management, planning, design, development, and governance in line with the long-term vision of sustainability under what is labeled "smart sustainable cities"([7-9, 12, 16, 17, 19], Bibri and Krogstie 2017c). This wave of research revolves around integrating the landscapes of, and the approaches to, sustainable cities and smart cities in a variety of ways in the hopes of reaching the required level of sustainability and improving the living standard of citizens [13]. This integrated approach tends to take several forms in terms of combining the strengths of sustainable cities and smart cities based on how the concept of smart sustainable cities can 
be conceptualized and operationalized, just as it has been the case for sustainable cities. Indeed, several topical studies (e.g., [3, 7, 8, 13, 17, 49, 50, 62, 68, 81]) have addressed the merger of the sustainable city and smart city approaches from a variety of perspectives. Accordingly, there is a host of opportunities yet to explore towards new approaches to smart sustainable urbanism. The focus in this paper is on integrating the design principles and planning practices of sustainable urban forms with big data computing and the underpinning technologies and their novel applications being offered by smart cities of the future. The underlying assumption is that the evolving big data deluge with its extensive sources hides in itself the answers to the most challenging analytical questions as well as the solutions to the most complex challenges pertaining to sustainability in the face of urbanization. It also plays a key role in understanding urban constituents as data agents.

In recent years, there has been a marked intensification of datafication. This is manifested in a radical expansion in the volume, range, variety, and granularity of the data being generated about urban environments and citizens (e.g., [46-48]), with the primary aim of quantifying the whole of the city, putting it in a data format so it can be organized and analyzed [13]. We are currently experiencing the accelerated datafication of the city in a rapidly urbanizing world and witnessing the dawn of the big data era not out of the window, but in everyday life. Our urban everydayness is entangled with data sensing, data processing, and communication networking, and our wired world generates and analyzes overwhelming and incredible amounts of data. The modern city is turning into constellations of instruments and computers across many scales and morphing into a haze of software instructions, which are becoming essential to the operational functioning, planning, design, development, and governance of the city. The datafication of spatiotemporal citywide events has become a salient factor for the practice of smart sustainable urbanism.

As a consequence of datafication, a new era is presently unfolding wherein smart sustainable urbanism is increasingly becoming data-driven. At the heart of such urbanism is a computational understanding of urban systems and processes that renders urban life a form of logical rules and algorithmic procedures-which is underpinned and informed by data-intensive scientific approaches to urban science and urban sustainability, while also harnessing urban big data to provide a more holistic and integrated view and synoptic intelligence of the city [13]. This is increasingly directed towards improving, advancing, and maintaining the contribution of sustainable cities to the goals of sustainable development in an increasingly urbanized world.

We are living at the dawn of what has been termed as "the fourth paradigm of science," a scientific revolution that is marked by the recent emergence of big data science and analytics as well as the increasing adoption and use of the underlying technologies in scientific and scholarly research practices. Everything about science development and knowledge production is fundamentally changing thanks to the unfolding and soaring data deluge. The upcoming data avalanche is thus the primary fuel of this new age, which powerful computational processes or analytics algorithms are using to generate useful knowledge and deep insights pertaining to a wide variety of practical uses.

As a new area of science and technology, "big data science and analytics embodies an unprecedentedly transformative power-which is manifested not only in the form of revolutionizing science and transforming knowledge, but also in advancing social practices, catalyzing major shifts, and fostering societal transitions. Of particular relevance, it is instigating a massive change in the way both sustainable cities and smart cities are understood, studied, planned, operated, and managed to improve and maintain sustainability in the face of expanding urbanization" ([14], p. 79). To put it differently, these practices are becoming highly responsive to a form of data-driven urbanism that is the key mode of production for what have been termed smart sustainable cities whose monitoring, understanding, and analysis are increasingly relying on big data technologies.

In a nutshell, the Fourth Scientific Revolution is set to erupt in cities, break out suddenly and dramatically, throughout the world. This is manifested in bits meeting bricks on a vast scale as instrumentation, datafication, and computerization are permeating the spaces we live in. The outcome will impact most aspects of urban life, raising questions and issues of urgent concern, especially those related to sustainability and urbanization. This pertains to what dimensions of cities will be most affected; how urban planning, design, development, and governance should change and evolve; and, most importantly, how cities can embrace and prepare for looming technological disruptions and opportunities.

In light of the above, at the beginning of a new decade, we have the opportunity to look forward and consider what we could achieve in the coming years in the era of big data revolution. Again, we have the chance to consider the desired future of data-driven smart sustainable cities. This will motivate many urban scholars, scientists, and practitioners to think about how the subject of "data-driven smart sustainable cities" might develop, as well as inspire them into a quest for the immense opportunities and fascinating possibilities that can be created by the development and implementation of such cities. In this respect, we are in the midst of an expansion of time horizons in city planning. Sustainable cities look further into the future when forming scenarios and 
strategies to achieve them. The movement towards a long-term vision arises from three major mega trends or macro-shifts that shape our societies at a growing pace: sustainability, ICT, and urbanization. Recognizing a link between such trends, sustainable cities across the globe have adopted ambitious goals that extend far into the future and developed different pathways to achieve them.

\section{Backcasting as a scholarly approach to strategic smart sustainable city planning and development}

As a special kind of scenario methodology, backcasting is applied here to build a future model for smart sustainable cities as a planning tool for facilitating urban sustainability. Backcasting scenarios are used to explore future uncertainties, create opportunities, build capabilities, and improve decision-making processes. Their primary aim is to discover alternative pathways through which a desirable future can be reached. Following Rotmans et al.'s [65] taxonomy, scenarios can be classified into different categories, including projective and prospective scenarios, qualitative and quantitative scenarios, participatory and expert scenarios, and descriptive and normative scenarios. This futures study is concerned with a normative scenario, which takes values and interests (sustainability and big data technology) into account and involves reasoning from specific long-term goals that have to be achieved.

In general, the backcasting approach is applicable in futures studies dealing with the fundamental question of backcasting, which involves the kind of actions that must be taken to achieve a long-term goal. In this context, if we want to attain a smart sustainable city, what actions must be taken to get there? Here backcasting means to look at the current situation from a future perspective. As an analytical and deliberative process (Fig. 1), backcasting entails articulating an end vision and then developing a pathway to get from the present to that endpoint. In more detail, the backcasting scenario is constructed from the distant future towards the present by defining a desirable future and then moving step-bystep backwards towards the present to identify the strategic steps that need to be taken to attain that specified future. This involves identifying the stumbling blocks on the way and the key stakeholders that should be involved to drive change, as well as developing and assessing the policy pathway in terms of planning practices and development strategies necessary to achieve the future outcome. The use of backcasting in futures studies assumes a vision of an evolutionary process of policy with a time frame of a generation or so, which is a basic principle to allow the policy actions to pursue the path towards, and potentially achieve, a sustainable future. Moreover, in urban sustainability, planning is about figuring out the 'next steps' which are quite literally the next concrete actions to undertake. Next steps are usually based on reacting to present circumstances, creativity, intuition, and common sense, but also (conceivably) are still aligned with the future vision and direction. Therefore, researchers in backcasting should not get obsessed with the next steps without considering how aligned they are with what they ultimately aim to achieve.

Figure 1 illustrates the backcasting process in which the future desired conditions are envisioned and steps are then defined to attain those conditions. In this regard, envisioning the smart sustainable city as a future vision has a normative side: what future is desired? Backcasting this preferred vision has an analytical side: how can this desirable future be attained? Backcasting is about analyzing possible ways of attaining certain futures as well as their feasibility and potential [56]. Specifically, in the quest for the answer to how to reach specified outcomes in the future, backcasting involves finding ways of linking goals that may lie far ahead in the future to a set of steps to be taken now and designed to achieve that end, and also facilitates discovery [29].

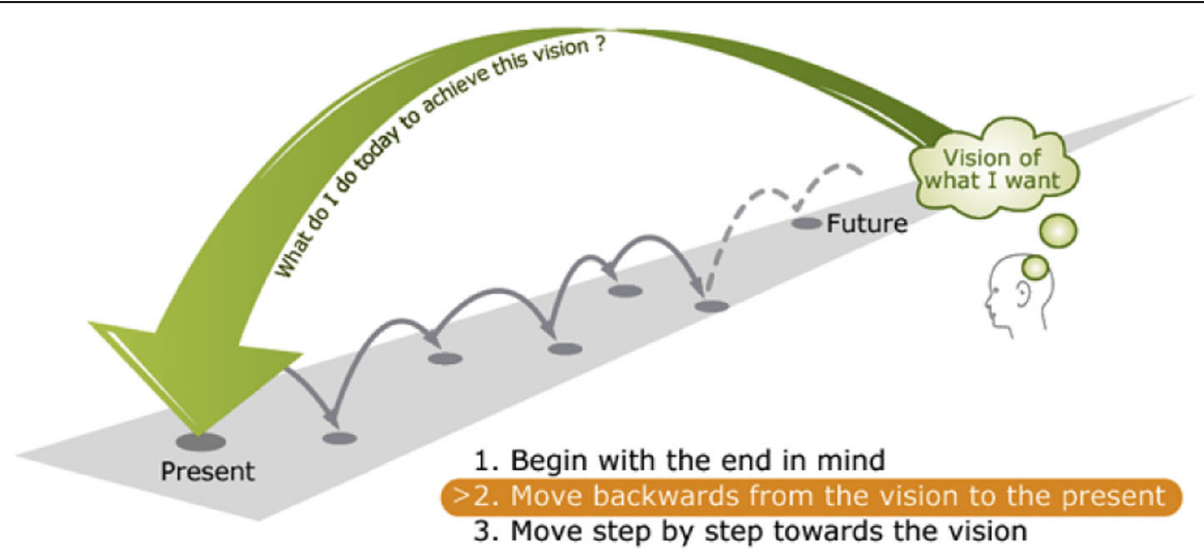

Fig. 1 The backcasting process from the natural step. Source: Holmberg [37] 
Backcasting is viewed as a natural step in operationalizing sustainable development [38] within different societal spheres. In terms of its practical application, backcasting is increasingly used in futures studies in the fields related to sustainable urban planning as a formal element of future strategic initiatives. It is the most applied approach in futures studies when it comes to sustainability problems and the identification and exploration of their solutions. This involves a wide variety of areas, including strategic city planning (e.g., [59]), sustainable city design [23]. transportation and mobility (Banister et al. 2000), sustainable transportation systems (Akerman and Höjer 2006; [39, 66]), sustainable technologies and sustainable system innovation [76], sustainable household (Green and Vergragt 2002; [57]), and sustainable transformation of organizations [37]. Backcasting studies must reflect solutions to a specified social problem in the broader sense [29]. Bibri [10] concludes that the backcasting approach is found to be well-suited for long-term urban sustainability problems and solutions due to its normative, goal-oriented, and problem-solving character. Generally, as argued by Dreborg [29], backcasting is particularly useful when:

- The problem to be studied is complex and there is a need for major change

- The dominant trends are part of the problem

- The problem to a great extent is a matter of externalities

- The scope is wide enough and time horizon is long enough to leave considerable room for deliberate and different choices and directions of development.

Bibri [10] has recently conducted a comprehensive study on futures studies and related approaches. Its main focus is on backcasting as a scholarly and planning approach to strategic smart sustainable city development. Its main objectives are to review the existing backcasting methodologies and to discuss the relevance of their use in terms of their steps and guiding questions for analyzing, investigating, and developing smart sustainable cities, as well as to synthesize a backcasting approach based on a number of notable future studies. Later, Bibri and Krogstie [19] adapted the approach, i.e., made minor changes so as to improve and clarify it in accordance with the overall aim of this futures study as well as the specificity of the proposed model. Indeed, a commonly held view is that the researchers' worldview and purpose remain the most important criteria for determining how futures studies can be developed and conducted in terms of the details concerning the questions guiding the steps involved in a particular backcasting approach. This helps to identify and implement strategic decisions associated with urban sustainability. However, the outcome of the adapted synthesized approach is illustrated in Table 1.
As the focus in this paper is on step 3, it is important to point out that the backcasting approach is traditionally based on one normative vision, but multiple visions can also be used to explore different future alternatives (e.g., [72]). In this futures study, step 3 of backcasting constructs only one future vision based on the objectives, goals, and targets specified in step 1, indicating an integrated solution to a set of problems and challenges associated with existing sustainable urban forms, with support of advanced technologies. In addition, the development of the future vision is typically performed after the stage of analyzing the current situation and assessing the external factors (steps 1 and 2 of the backcasting study). While some views defend that a prior evaluation grounds the vision in realism, others argue that it curtails the ability to think of "ideal states" by putting the current circumstances and capabilities at the center of attention. However, this prescribed vision of the future is based on a sequential progression into the future of the current trends and the expected developments and the way they intertwine with and affect one another in relation to smart sustainable cities, without sharp transformation. It is also based on a combination of technological innovations and sustainability advancements, or on the co-evolutionary pathways of social and ecological systems.

\section{Future vision generation}

Constructing the future vision entails defining and describing a desirable future in which the problems and issues identified in relation to existing sustainable urban forms have been solved by meeting the stated objectives and thus achieving the specified goals and targets described in step 1 (see [19] for a detailed account and discussion). In general, future vision construction is about identifying the desired future state, which consists of vibrant descriptions of audacious goals and targets, as well as reflective statements addressing the aspired future. It is important to note at this stage that the vision of the future and the proposed novel model tend to be used interchangeably in this paper. Indeed, this vision represents a short and concise version of this model. In other words, this model entails a desired future state that is supposed to be more detailed at the end of this scholarly backcasting endeavor.

\section{On the visionary approach (see guiding question 1)}

The future vision is a result of the concept of urban sustainability as clarified, advocated, and advanced by many scholars, academics, theorists, and practitioners in the field, and demonstrated in numerous real-world cities across the globe, especially within ecologically advanced nations. According to several rankings, Sweden, Norway, Finland, Germany, and the Netherlands have the highest 
Table 1 The guiding questions for each step in the backcasting study

\begin{tabular}{ll}
\hline Questions for backcasting steps & Methods \\
\hline Step 1: Detail strategic problem orientation (part 1) & Study design and problem \\
1. What is the socio-technical system to be studied? & Whion \\
2. What are the aim, purpose, and objectives of the futures study in relation to this system? & 3hat are the long-term targets declared by the goal-oriented backcasting approach? \\
4. What are the goals of sustainability these targets are translated to for scenario analysis?
\end{tabular}

Step 2: Detail strategic problem orientation (part 2)

1. What are the key trends and expected developments related to the socio-technical system to be studied? Trend analysis and problem analysis

2. What are the major problems, issues, and challenges of sustainability and the underlying causes-the current situation?

3. How is the problem defined and what are the possible problem perceptions?

Step 3: Generate a sustainable future vision

Creativity method

1. What are the demands (terms of reference) for the future vision?

2. How does the future sustainable socio-technical system and need fulfillment look like?

3. How is the future vision different from the existing socio-technical systems?

4. What is the rationale for developing the future vision?

5. Which sustainability problems, issues, and challenges have been solved

6. or mitigated by meeting the stated objectives and thus achieving the specified targets and goals?

7. Which advanced technologies and their novel applications have been

8. used in the future vision?

Step 4: Conduct empirical research

Case study method

1. What category of case studies is most relevant to the future vision?

2. How many case studies are to be conducted and what kind of phenomena do they intend to illuminate?

3. What is the rationale for the methodological approach adopted?

4. To what extent can this empirical research generate new ideas and serve to illustrate the theories and their effects underlying the future vision so as to underpin its potential and practicality?

Step 5: Specify and merge the components of the socio-technical system to be developed

Creativity method

1. What specific design concepts, planning practices, and technology elements are necessary?

2. What kind of urban centers and labs are necessary?

3. What spatial dimensions and scale stabilizations should be considered?

4. How can all of the ingredients be integrated into a model for strategic smart sustainable city planning and development?

Step 6: Perform backcasting backward-looking analysis

Backcasting analysis

1. What urban and technological changes are necessary for achieving the future vision?

2. What structural, institutional, and regulatory changes are necessary?

3. How have the necessary changes been realized and what stakeholders are necessary?

4. What are the opportunities, potentials, benefits, and other effects of the future vision?

level of sustainable development practices (e.g, [30]). However, the development of the novel model for smart sustainable cities of the future is supported by several case studies from Sweden as well as their integration in terms of the planning practices and development strategies through which sustainable urban forms can be achieved. Additionally, this model involves the way instrumentation, datafication, and computerization are opening up dramatically different forms of optimizing and enhancing the performance of such forms, thereby increasing their contribution to the goals of sustainable development. This entails the ways in which the informational landscape of smart cities as underpinned by big data technologies and their novel applications can be 
integrated with the physical landscape of sustainable cities, and what this implies in regard to increasing their sustainability benefits. The essence of the idea revolves around the need to harness, analyze, and leverage the deluge of urban data that has hitherto been mostly associated with smart cities but has clear synergies in the functioning, planning, and development of sustainable cities in terms of improving, advancing, and maintaining their contribution to sustainability.

The problems and issues that the sustainable city faces today will, especially if its landscape and strategy continues to be extremely fragmented from and weakly connected with those of the smart city at the technical and policy levels, increase in the future with possibly much greater compounding effects due to the rapid urbanization of the world and the mounting challenges of sustainability in a rather increasingly technologized and computerized world. As a scholarly endeavor, the development of the novel model for smart sustainable cities of the future as a holistic approach to city planning and development is primarily aimed at bringing together and interlinking the sustainable city and smart city landscapes and strategies so as to address and overcome a set of challenging problems associated with the existing sustainable urban forms. This requires finding more creative and effective ways of merging sustainability knowledge with advanced technologies to enhance the performance of such forms in the face of urbanization using cutting-edge technologies. This can be accomplished by amalgamating the compact city with the ecocity into one model of sustainable urban form in terms of the underlying typologies and design concepts as planning practices, and then augmenting this model with big data technologies and their novel applications as a set of innovative solutions and sophisticated approaches being offered by the data-driven city. In this respect, city operating system, operations centers, innovation and living labs, and strategic planning and policy offices will handle the activity of generating, processing, and analyzing the data deluge aimed at adopting those innovation solutions and sophisticated approaches in the context of the smart sustainable city. Practical uses and applications in this regard span a range of urban systems and domains in terms of operations, functions, services, designs, strategies, and policies with respect to sustainability.

The future vision has a high expectation on big data technology to deliver the needed solutions and approaches to meet the optimal level of sustainability and enable the built environment to function in a more constructive way than at present in terms of lowering energy consumption, mitigating pollution, and minimizing waste, as well as in terms of improving equity, inclusion, and the quality of life. This is to be determined by whether and the extent to which a given city is currently badging or regenerating itself as, or manifestly planning to be, sustainable or smart sustainable. And what this entails in terms of long-term targets of sustainable development as set by that city, in particular in connection with its design concepts, typologies, spatial organizations, and scale stabilizations as planning practices. In the short term, although big data technology could theoretically help meet the optimal level of sustainability and enable the instrumentation, datafication, and computerization of the built environment towards purposeful urban functioning and planning, this would be difficult and expensive. Nevertheless, the future vision can be feasible because it has to be realized over the long run.

The technological vision is based on the assumption of a full development, integration, and deployment of big data computing and the underpinning technologies which exist today and are likely to become widely available in the years ahead to achieve the sought goals. The incorporation of these advanced technologies into urban environments is supported by their untapped potential for and proven role in overcoming the problems and challenges of urbanization and sustainability. In this respect, big data computing and the underpinning technologies will be determining in the process of redesigning and restructuring urban places to achieve the optimal level of sustainability.

\section{The future vision (see guiding question 2)}

The key goal to be necessarily present in any backcasting endeavor is generating the normative alternative for the future and, as related to step 5 which is to be addressed in one of the upcoming papers, analyzing its opportunities, potentials, environmental and social benefits, and other effects.

Taking the prevailing and emerging trends to the extreme with the main expected developments (the outcome of step 2) in mind, we singled out one major societal driver for one scenario: a situation that is most likely to happen in the future:

A scenario where innovations and advancements in big data science and analytics and the underpinning technologies as a disruptive form of science and technology dramatically changes the rules by which society functions on a global scale.

Accordingly, the futures study envisions the smart sustainable city as:

A form for human settlements that will be able to improve, advance, and maintain its contribution to the goals of sustainable development by being pervaded, monitored, understood, and analyzed by advanced ICT. As such, it is to be realised by the planning practices and design strategies pertaining 
to the most advocated and prevalent models of sustainable urban form as integrated-as well as underpinned by big data computing and the underlying core enabling technologies in terms of the instrumentation, datafication, and analytics of the built environment. Related sophisticated approaches and novel applications will be developed, applied, and enhanced by a number of strategic urban actors, including urban operations centers, urban services agencies, strategic planning and design offices, policymaking bodies, research centers, and innovation and living labs. The main strategic goal of the future model of data-driven smart sustainable urban form is to secure and uphold environmentally sound, socially beneficial, and economically viable development towards achieving sustainability.

In light of the above, envisaging the smart sustainable city of the future focuses on the urban and technological components and how they should be integrated that make the city functions as a smart sustainable entity as well as a social organism. Central to this quest is the idea of big data computing and the underpinning technologies as an advanced form of ICT penetrating wherever and whatever it can of the built environment to improve and sustain the performance of what and how urban stakeholders can envision and enact in terms of new forms of cities with regard to sustainability. Furthermore, advanced ICT comes into play as a response to the commonly held view that cities should be conceived in terms of both urban strategies and processual outcomes of urbanization, which involves questions related to the behavior of inhabitants; the processes of living, consuming, and producing; and the processes of building urban environments-in terms of whether these are sustainable. The underlying assumption is that conceiving cities only in terms of, or accounting only for, urban strategies to make cities more sustainable remains inadequate to achieve the elusive goals of sustainable development.

The three strands of the model for smart Sustainable City of the future (see guiding question 3 )

As hinted at above, the novel model for smart sustainable cities of the future, the more detailed version of the future vision, integrates two models of sustainable urban form: the compact city and the eco-city, with the data-driven city. This will result in a holistic approach to urbanism, which is different, to a great extent, from these cities taken separately as existing approaches to urbanism. Worth pointing out, to reiterate, is that the focus of this amalgamation is on the design concepts and typologies characterizing both the compact city (i.e., compactness, density, diversity, mixed-land use, and sustainable transport) and the eco-city (i.e., renewable resources, passive solar design, ecological and cultural diversity, greening, environmental management, and other key environmentally sound policies) together with the innovative solutions and sophisticated approaches being offered by big data technologies and their novel applications for sustainability, which relate to the data-driven city and its components (i.e., urban operating centers, research centers, living labs, and innovation labs). The nature and scope of this amalgamation are to be determined by how and the extent to which the characteristic features of the data-driven city would dovetail with those of the integrated model of sustainable urban form towards producing what can be described asdata-driven smart sustainable urban form. The possible steps to be taken to attain the smart sustainable city of the future as a desired end-point or future vision is rather the object of step 5 of the backcasting approach, which comes after step 4 . This step is concerned with the case studies that need to be performed to strengthen the future vision and thus the novel model with empirical investigation. The guiding questions of these two steps are listed in Table 1.

Furthermore, it must be noted that there are neither real examples of a truly smart sustainable city that have actually been delivered and thus no precedents to reference, nor future-proofing of the big data technology to ensure that it is able to be adapted, modified, and built upon in an effective way over the next 25 years or so in response to the dynamic changes of technology and fast-moving hitech industry. Therefore, the planned big data technology solutions must be evaluated through actual implementation and its successfulness in order to outline the actual opportunity pertaining to the improvement and advancement of urban sustainability. Indeed, big data computing and the underpinning technologies intended to support the smart sustainable city of the future are currently evolving along with those experts and professionals who are needed to support and operate them; sustainability objectives, goals, and directives are increasingly being, and should continue to be, supported and facilitated using this advanced technology as much as possible across urban domains in terms of operations, functions, services, designs, strategies, and policies; and citizens and communities must be involved and engaged with big data technology and related platforms on a far broader scale. The road ahead promises to be an exciting one as more cities become aware of the great potential and clear prospect of integrating the smart city and the sustainable city as landscapes and strategies. In the sequel, we describe the 
three strands that comprise the novel model for smart sustainable cities of the future as hinted at in the description of the vision of the future above.

\section{Sustainable cities}

There are multiple views on what a sustainable city should be or look like and thus various ways of defining or conceptualizing it. Generally, a sustainable city can be understood as a set of approaches into operationalizing sustainable development in, or practically applying the knowledge about sustainability and related technologies to the planning and design of, existing and new cities or districts. It represents an instance of sustainable urban development, a strategic approach to achieving the longterm goals of urban sustainability. Accordingly, it needs to balance between the environmental, social, and economic goals of sustainability as an integrated process. Specifically, as put succinctly by [11], p. 11), a sustainable city "strives to maximize the efficiency of energy and material use, create a zero-waste system, support renewable energy production and consumption, promote carbon-neutrality and reduce pollution, decrease transport needs and encourage walking and cycling, provide efficient and sustainable transport, preserve ecosystems and green space, emphasize design scalability and spatial proximity, and promote livability and communityoriented human environments."

There are different instances of sustainable cities as an umbrella term, which are identified as models of sustainable urban forms, including compact cities, eco-cities, sustainable urbanism, green urbanism, new urbanism, and urban containment, with the first two being often advocated as the most sustainable and environmentally sound models [13]. In addition, Jabareen [40] ranks compact cities as more sustainable than eco-cities from a conceptual perspective using a thematic analysis. However, the effects of these models are compatible with the goals of sustainable development in terms of transport provision, mobility and accessibility, travel behavior, energy conservation, pollution and waste reduction, economic viability, life quality, and social equity. Furthermore, there are multiple definitions of compact cities and eco-cities in the literature (e.g., [40-45, 54, 60, 61, 64, 74]). These definitions tend to be based on the wider socio-cultural context in which these models of sustainable urban form are embedded in the form of projects and initiatives and related objectives, requirements, resources, and capabilities. In other words, there is a diversity underneath the various uses of the term compact city and eco-city, as well as a convergence or divergence in the way projects and initiatives conceive of what these city approaches should be.

The compact city model The concept of the compact city became widespread in the early 1990s as a result of the near clinical separation of land uses because of suburban sprawl that had risen the need for mobility, creating an upsurge in automobile use, which in turn caused high levels of air and noise pollution, as well as decaying city centers. In the 1990s, the European Commission highlighted a number of negative trends in urban development in their Green Paper on the Urban Environment [24], and therefore argued for denser development, mixed land use, and the transformation of former brownfield sites rather than development in open green areas. Fundamentally, the compact city is characterized by high-density and mixed-land use with no sprawl $[41,42,80]$ through the intensification of development, i.e., infill, renewal, redevelopment, and so on. It was around the mid-1990s when the research led to the advocacy of combining compactness and mixed-land use [40]. Mixed-land use should be encouraged in cities [21]. In addition, the compact city emphasizes spatial diversity, social mix, sustainable transportation (e.g., transit-rich interconnected nodes), as well as high standards of environmental and urban management systems, energy-efficient buildings, closeness to local squares, more space for bikes and pedestrians, and green areas [17, 19]. It has been addressed and can be implemented at different levels, namely neighborhood, district, city, metropolitan, and region, and involves many strategies that can avoid all the problems of modernist design in cities by enhancing the underlying environmental, social, and economic justifications and drivers. Neuman [54] identifies and enumerates the key dimensions of the compact city in Table 2 .

Table 2 Compact city dimensions. Source: Neuman [54]

Compact city dimensions
1. High residential and employment densities
2. Mixture of land uses
3. Fine grain of land uses (proximity of varied uses and small relative
size of land parcels)
4. Increased social and economic interactions
5. Contiguous development (some parcels/structures may be vacant or
abandoned or surface parking)
6. Contained urban development, demarcated by legible limits
7. Urban infrastructure, especially sewerage and water mains
8. Multimodal transportation
9. High degrees of accessibility: local/regional
10. High degrees of street connectivity (internal/external), including
sidewalks and bicycle lanes
11. High degree of impervious surface coverage
12. Low open-space ratio
13. Unitary control of planning of land development, or closely
coordinated control
14. Sufficient government fiscal capacity to finance urban facilities and
infrastructure


The compact city is more energy efficient and less polluting because people live in close proximity to workplaces, shops, and leisure and service facilities, which enables them to walk, bike, or take transit. This is in turn anticipated to create a better quality of life by creating more social interaction, community spirit, and cultural vitality (Jenks and Jones 2010). Further, travel distances between activities are shortened due to the heterogeneous zoning that enables compatible land uses to locate in close proximity to one another-mixed-land uses. Such zoning primarily reduces the use of automobiles (car dependency) for commuting, leisure, and shopping trips [1, 75]. Integrating land use, transport, and environmental planning is key to minimizing the need for travel and to promoting efficient modes of transport [67]. Transport systems play particularly an important role in the livability of contemporary cities [55]. The interrelationship between transport, people, and amenities are argued to be the vital elements of the microstructure of a sustainable city [32]. Important to note is that population densities are sufficient for supporting local services and businesses [80] in terms of economic viability. In high-density development, more land is available for green and agricultural areas, public transport services are superior, and the environmental footprint of the nonrenewable resource consumption is steady [69].

In sum, the compact city model has been advocated as more sustainable urban form due to several reasons: "First, compact cities are argued to be efficient for more sustainable modes of transport. Second, compact cities are seen as a sustainable use of land. By reducing sprawl, land in the countryside is preserved and land in towns can be recycled for development. Third, in social terms, compactness and mixed uses are associated with diversity, social cohesion, and cultural development. Some also argue that it is an equitable form because it offers good accessibility. Fourth, compact cities are argued to be economically viable because infrastructure, such as roads and street lighting, can be provided cost-effectively per capita." ([40], p. 46).

The eco-city model The idea of the eco-city is widely varied in conceptualization and operationalization, and also difficult to delineate. According to the most comprehensive survey of eco-cities to date performed by Joss [43], the diversity and plurality of the projects and initiatives reflected in the use of the term "eco-city" across the globe make it difficult to develop a meaningful definition. Therefore, the concept of the eco-city has taken on many definitions in the literature. Richard Register, an architect widely credited as the first to have coined the term, describes an eco-city as "an urban environmental system in which input (of resources) and output (of waste) are minimized" [61]. Joss [44] states that an eco-city must be, using three analytical categories, developed on a substantial scale, occurring across multiple domains, and supported by policy processes. As an umbrella metaphor, the eco-city "encompasses a wide range of urban-ecological proposals that aim to achieve urban sustainability. These approaches propose a wide range of environmental, social, and institutional policies that are directed to managing urban spaces to achieve sustainability. This type promotes the ecological agenda and emphasizes environmental management through a set of institutional and policy tools." ([40], p. 47) This implies that realizing an eco-city requires making countless decisions about urban design, governance, sustainable technologies, and so on [60]. This in turn signifies that the relationship between sustainable development objectives and urban planning interventions is a subject of much debate [22, 79].

Irrespective of the way the idea of the eco-city has been conceptualized and operationalized, there are still some criteria that have been proposed to identify what a desirable or ideal "eco-city" is or looks like, comprising the environmental, social and economic goals of sustainable development. Roseland [64] and Harvey [35] describe an ideal "eco-city" as a city that fulfills the following requirements:

- Operates on a self-contained local economy that obtains resources locally

- Maximizes energy and water efficiency, thereby promoting conservation of resources

- Manages an ecologically beneficial waste management system that promotes recycling and reuse to create a zero-waste system

- Promotes the use and production of renewable energy, thereby being entirely carbon-neutral

- Has a well-designed urban city layout that promotes walkability, biking, and the use of public transportation systems

- Ensures decent and affordable housing for all socioeconomic and ethnic groups and improves jobs opportunities for disadvantaged groups

- Supports urban and local farming

- Supports future progress and expansion over time.

As added by Graedel [33], the eco-city is scalable and evolvable in design in response to urban growth and need changes. Based on these characteristic features, the eco-city and green urbanism overlap or share several concepts, ideas, and visions in terms of the role of the city and positive urbanism in shaping more sustainable places, communities, and lifestyles [5], pp. 6-8, cited in [40]) views, while arguing for the need for new approaches to urbanism to incorporate more ecologically responsible forms of living and settlement, a city exemplifying green urbanism as one that: 
- strives to live within its ecological limits;

- is designed to function in ways analogous to nature;

- strives to achieve a circular rather than a linear metabolism;

- strives towards local and regional self-sufficiency;

- facilitates more sustainable lifestyles; and

- emphasizes a high quality of neighborhood and community life.

The eco-city approaches tend to emphasize different aspects of sustainability, namely passive solar design, greening, sustainable housing, sustainable urban living, and living machines [40]. Worth noting is that, as a general consensus, the eco-city is eco-amorphous (formless) in terms of typologies, although it emphasizes passive solar and ecological design [40]. Indeed, it is evident that the form specificities are on less focus in eco-city development. That is to say, the built environment of the city in terms of urban design features and spatial organizations is insignificant, unlike the compact city which focuses on the spatial patterns of physical objects. Rather, what counts most is how the city as a social fabric is organized, managed, and governed. In this line of thinking, [70], p. 37), state, 'social, economic, and cultural variables are far more important in determining the good city than any choice of spatial arrangements.' In view of that, the focus is on the role of different environmental, social, economic, institutional, and land use policies in managing and governing the city to achieve the required level of sustainability (e.g., [25, 40, 63]).

\section{The data-driven city and its smart and sustainable dimensions}

"Data-driven smart sustainable cities" is a term that has recently gained traction in academia, government, and industry to describe cities that are increasingly composed and monitored by ICT of ubiquitous and pervasive computing and thus have the ability of using advanced technologies by city operations centers, strategic planning and policy offices, research centers, innovation labs, and living labs for generating, processing, and analyzing the data deluge in order to enhance decision making processes and to develop and implement innovative solutions for improving sustainability, efficiency, resilience, equity, and the quality of life [13]. It entails developing a citywide instrumented system (i.e., inter-agency control, planning, innovation, and research hubs) for creating and inventing the future. For example, a data-driven city operations center, which is designed to monitor the city as a whole, pulls or brings together real-time data streams from many different agencies spread across various urban domains and then analyze them for decision making and problem solving purposes: optimizing, regulating, and managing urban operations (e.g., traffic, transport, mobility, energy, etc.).

As cities are routinely embedded with all kinds of ICT forms, including infrastructures, platforms, systems, devices, sensors and actuators, and networks, the volume of data generated about them is growing exponentially and diversifying, providing rich, heterogenous streams of information about urban environments and citizens. This data deluge enables a real-time analysis of different urban systems and interconnects data to provide detailed views of the relationships between various forms of data that can be utilized for improving the various aspects of urbanity through new modes of operational functioning, planning, development, and governance in the context of sustainability.

On the evolving integration of data-driven, smart, and sustainable cities Cities are becoming ever more computationally augmented and digitally instrumented and networked, their systems interlinked and integrated, their domains combined and coordinated, and their networks coupled and interconnected, and consequently, vast troves of urban data are being generated and used to regulate, control, manage, and organize urban life in real time. In other words, the increasing pervasiveness of urban systems, domains, and networks utilizing digital technologies is generating enormous amounts of digital traces capable of reflecting in real time how people make use of urban spaces and infrastructures and how urban activities and processes are performed. This informational asset is being leveraged in steering cities. Indeed, citizens leave their digital traces just about everywhere they go, both voluntarily and involuntarily, and when cross-referenced with each citizen's spatial, temporal, and geographical contexts, the data harnessed at this scale offers a means of describing, and responding to, the dynamics of the city in real time. In addition to individual citizens, city systems, domains, and networks constitute the main source of data deluge, which is generated by various urban entities, including governmental agencies, authorities, administrators, institutions, organizations, enterprises, and communities by means of urban operations, functions, services, designs, strategies, and policies.

Smart cities are increasingly connecting the ICT infrastructure, the physical infrastructure, the social infrastructure, and the economic infrastructure to leverage their collective intelligence, thereby striving to render themselves more sustainable, efficient, functional, resilient, livable, and equitable. It follows that smart cities of the future seek to solve a fundamental conundrum of cities-ensure sustainable socio-economic development, equity, and enhanced quality-of-life at the same time as reducing costs and increasing resource efficiency and 
environment and infrastructure resilience. This is increasingly enabled by utilizing a fast-flowing torrent of urban data and the rapidly evolving data analytics technologies; algorithmic planning and governance; and responsive, networked urban systems. In particular, the generation of colossal amounts of data and the development of sophisticated data analytics for understanding, monitoring, probing, regulating, and planning the city are significant aspects of smart cities that are being embraced by sustainable cities to improve, advance, and maintain their contribution to the goals of sustainable development (e.g., $[8,13,17,18])$. Indeed, there has recently been much enthusiasm in the domain of smart sustainable urbanism about the immense possibilities and fascinating opportunities created by the data deluge and its extensive sources with regard to optimizing and enhancing urban operational functioning, management, planning, design, and development in line with the goals of sustainable development as a result of thinking about and understanding sustainability and urbanization and their relationships in a data-analytic fashion for the purpose of generating and applying knowledge-driven, factbased, strategic decisions in relation to such urban domains as transport, traffic, mobility, energy, environment, education, healthcare, public safety, public services, governance, and science and innovation. For supra-national states, national governments, and city officials, smart cities offer the enticing potential of environmental and socio-economic development, and the renewal of urban centers as hubs of innovation and research (e.g., [2, 4, 13, 19, 46, 51, 71]). While there are several main characteristics of a smart city as evidenced by industry and government literature (e.g., [36, 46] for an overview), the one that the futures study, and thus this paper, is concerned with focuses on environmental and social sustainability.

A framework for the data-driven smart sustainable city The framework for the data-driven smart sustainable city illustrated in Fig. 2 entails specialized urban, technological, organizational, and institutional elements dedicated for improving, advancing, and maintaining the contribution of such city to the goals of sustainable development [13]. It is derived based on thematic analysis and technical literature. This justifies the relationship between the underlying components. Furthermore, underlying the idea of the data-driven smart sustainable city is the process of drawing all the kinds of analytics associated with urban life into a single hub, supported by the broader public and open data analytics. This involves creating a city-wide instrumented or centralized system that draws together data streams from many agencies (across city domains) for large scale analytics and then direct them to different centers, labs, and offices. Urban operating systems explicitly link together multiple urban technologies to enable greater coordination of urban systems and domains. Urban operations centers attempt to draw together and interlink urban big data to provide integrated and holistic views and synoptic city intelligence through processing, analyzing, visualizing, and monitoring the vast deluge of urban data that can be used for real-time decision-making pertaining to sustainability by means of big data ecosystems. Strategic planning and policy centers serve as a data analytic hub to weave together data from many diverse agencies to control, manage, regulate, and govern urban life more efficiently and effectively in relation to sustainability. This entails an integration that enables systemwide effects to be understood, analyzed, tracked, and built into the very designs and responses that characterize urban operations, functions, and services. As far as research centers and innovation labs are concerned, they are associated with research and innovation for the purpose of developing and disseminating urban intelligence functions. For the anatomy of the datadriven smart sustainable city in terms of digital instrumentation, datafication, computerization, as well as urban operations centers, strategic planning and policy offices, living labs, innovations labs, urban intelligence functions, and so on, the reader can be directed to Bibri [15].

\section{The rationale behind developing the future vision (see guiding question 4)}

The arguments, a set of reasons given in support of the novel model for smart sustainable cities of the future, are compiled and distilled from the outcome of step 2 of the backcasting study conducted by Bibri and Krogstie [19]. There are many reasons for integrating the existing models of sustainable urban form as a set of practices, or many explanations of controlling the concepts and principles of these practice in the domain of urban sustainability. This applies also to the integration of the sustainable city and the data-driven city as different approaches to urbanism. Here, we identify the key reasons in relevance to the aim of the futures study. This is accordingly to justify the research pursuit of analyzing, investigating, and developing the proposed model for smart sustainable city of the future.

\section{Amalgamating the compact city model with the eco-city model}

- Being one of the most significant intellectual and practical challenges for three decades, the development of a desirable model of sustainable urban form continues to motivate and inspire collaboration between researchers, academics, and 


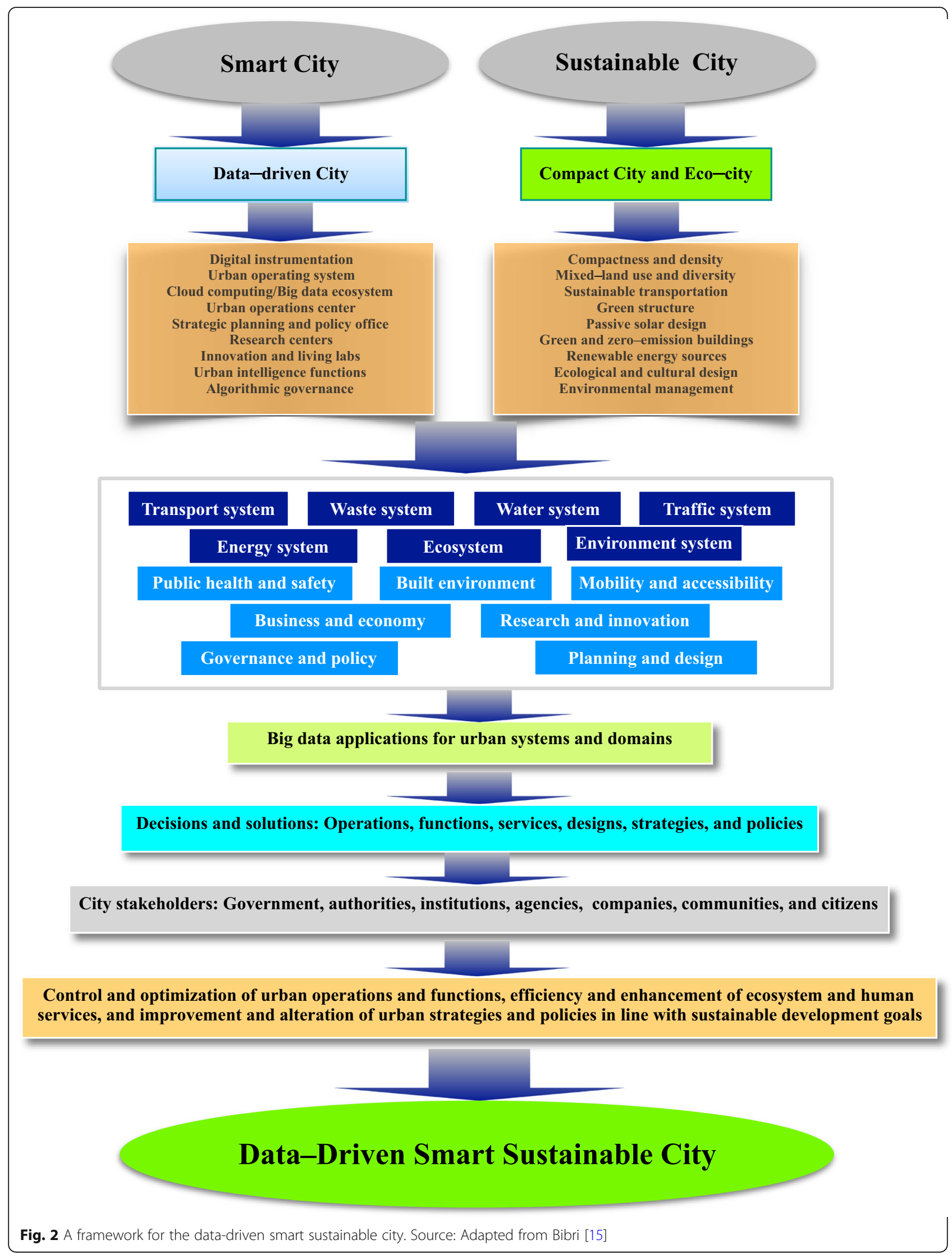


practitioners to create more effective design and planning solutions based on a more integrated and holistic perspective.

- Different scholars and planners may develop different combinations of design concepts to achieve the goals of sustainable development. They might come with different forms, where each form emphasizes different concepts and contributes differently to sustainability.

- Sustainable urban forms have many overlaps among them in their concepts, ideas, and visions. While there is nothing wrong with such forms being different yet compatible and not mutually exclusive, it can extremely be beneficial and strategic to find innovative ways of combining their distinctive concepts and key differences towards more holistic forms for improving sustainability performance.

- Compact cities have a form as they are governed by static planning and design tools, whereas eco-cities are amorphous: without a clearly defined form, thereby the feasibility and potential of their integra tion into one model that can eventually accelerate sustainable development towards achieving the optimal level of sustainability.

- Neither real-world cities nor academics have yet developed convincing models of sustainable urban form, and the components of such form are still not yet fully specified.

- More in-depth knowledge on planning practices is needed to capture the vision of sustainable urban development, so too is a deeper understanding of the multi-faceted processes of change to achieve sustainable urban forms. This entails conceptualizing multiple pathways towards attaining this vision and developing a deeper understanding of the interplay between social and technical solutions for sustainable urban forms.

\section{Merging the integrated model of sustainable urban form with the data-driven smart city model}

- Smart urbanism as being predominately driven by big data computing and the underpinning technologies has recently revived the debate about sustainable cities, and promises to add a whole new dimension to sustainability by enhancing the outcome of the design principles and strategies underlying the existing models of sustainable urban form in ways that enable such form to achieve the optimal level of sustainability.

- It is an urban world where the physical landscape of sustainable cities and the informational landscape of smart cities are increasingly being merged. Hence, it is high time for sustainable urban forms to embrace and leverage what data-driven smart cities have to offer in terms of innovative solutions and sophisti cated approaches to overcome the complex challenges of sustainability and urbanization.

- A large part of research within the emerging area of smart sustainable cities focuses on exploiting the potentials and opportunities of advanced technologies and their novel applications to mitigate or overcome the issue of sustainable cities and smart cities being extremely fragmented as landscapes and weakly connected as approaches, especially at the technical and policy levels.

- There is huge potential for using big data computing and the underpinning technologies to advance sustainable urban forms through novel approaches to decision support in the form of intelligence functions enabled by the analytical power of the deluge of urban data.

- Tremendous opportunities are available for utilizing big data applications in sustainable cities to optimize and enhance their operations, functions, services, designs, strategies, and policies, as well as to find answers to challenging analytical questions and thereby advance knowledge.

- As an integrated and holistic approach, smart sustainable cities tend to take multiple forms of combining the strengths of sustainable cities and smart cities based on how the concept of smart sustainable cities can be conceptualized and operationalized. As a corollary of this, there is a host of unexplored opportunities towards new approaches to smart sustainable urban development.

Problems, issues, and challenges (see guiding question 5) The issue of sustainable urban forms has always been problematic and daunting to deal with. In view of that, the intellectual challenge to produce a theoretically and practically convincing model of sustainable urban form with clear components continues to induce scholars, academics, planners, scientists, and real-world cities even to create a more successful and robust model of such form. In addition, the contribution of the existing models of sustainable urban form to sustainability has, over the last three decades or so, been subject to much debate, generating a growing level of criticism that essentially questions its practicality, intellectual foundation, and added value.

Developing the model for smart sustainable cities of the future is aimed at improving, advancing, and sustaining the contribution of sustainable urban forms to the goals of sustainable development with support of big data computing and the underpinning technologies as an advanced form of ICT. This is due to the underlying 
potential for enhancing and optimizing urban operations, functions, designs, services, strategies, and practices in line with the goals of sustainable development, as well as for solving a number of problems, addressing key issues, and overcoming complex challenges in the context of sustainable urban forms. These are distilled and compiled from an extensive interdisciplinary literature review and the outcome of step 2 of the backcasting study $([16,19])$ (Table 3$)$.
Key novel analytical and practical applications of big data technology for the future vision (see guiding question 6)

Big data applications are increasingly permeating the systems and domains of sustainable cities. This can be seen as a new ethos added to the era of sustainable urbanism in response to the rise of ICT and the spread of urbanization as major global shifts at play today. The characteristic spirit of this era is manifested in the behavior and aspiration of sustainable cities towards

Table 3 Problems, issues, and challenges pertaining to sustainable urban forms

What to solve, deal with, or Deficiencies, Limitations difficulties, fallacies, and uncertainties

overcome

Problems

- Not only in practice but also in theory have sustainable urban forms been problematic and daunting to deal with as manifested in the kind of the non-conclusive, limited, conflicting, contradictory, uncertain, and weak results of research obtained. This is partly due to the use of traditional collection and analysis methods and data scarcity. These results pertain particularly to the actual effects and benefits of sustainability as assumed or claimed to be delivered by the design principles and strategies adopted in planning and development practices.

- Sustainable urban forms fall short in considering smart solutions within many urban domains where such solutions could have substantial contributions to the different aspects of sustainability.

- Deficiencies in embedding various forms of advanced ICT into urban design and planning practices associated with sustainable urban forms.

- Sustainable urban forms remain static in planning conception, unscalable in design, inefficient in operational functioning, and ineffective in management without advanced ICT in response to urban growth, environmental pressures, changes in socio-economic needs, global shifts, discontinuities, and societal transitions.

- Realizing compact cities and eco-cities require making countless and complex decisions about green and energyefficient technologies, urban layouts, building design, and governance.

- Divergences in and uncertainties about what to consider and implement from the typologies and design concepts of models of sustainable urban form.

- Sustainable urban forms are in themselves very complex in terms of management, planning, design, and development, so too are their domains in terms of coordination and integration as well as their networks in terms of coupling and interconnection.

- Sustainable cities and smart cities are weakly connected as ideas, visions, and strategies as well as extremely fragmented as landscapes at the technical and policy levels.

- Sustainability goals and smartness targets are misunderstood as to their-rather clear-synergies.

- There is a need for solidifying the existing applied theoretical foundations in ways that provide an explanation for how the contribution of sustainable urban forms to sustainability can be improved and maintained on the basis of big data technology and its applications.

- There is no strategic framework for merging the informational and physical landscapes of the existing models of sustainable urban form.

Issues

- In relation to spatial scales, the existing models of sustainable urban forms tend to focus more on the neighbourhood level than on the city level in terms of design and planning due to the uncertainties surrounding the design principles and planning practices as to their actual sustainability effects and benefits.

- Conceiving cities only in terms of forms remains inadequate to achieve the goals of sustainable development. It should be informed by the processual outcomes of urbanization to attain these goals, as this involves asking the right questions related to the behavior of inhabitants; the processes of living, consuming, and producing; and the processes of building urban environments-in terms of whether these are sustainable.

- Cities evolve and change dynamically as complex systems and urban environments, so too is the underlying knowledge of design and planning that is historically determined to change perennially in response to new factors.

- In urban planning and policy making, sustainable cities have tended to focus mainly on infrastructures for urban metabolism —-sewage, water, energy, and waste management while falling short in considering innovative solutions and sophisticated methods for urban operational functioning, planning, design, and development.

- One of the most significant challenges is to integrate and augment sustainable urban forms with advanced technologies and their novel applications-in ways that enable them to improve, advance, and maintain its contribution to the goals of sustainable development.

- There are difficulties in translating sustainability into the built, infrastructural, and functional forms of cities.

- There are difficulties in evaluating the extent to which the existing models of sustainable urban form contribute to the goals of sustainable development. It is not an easy task to even judge whether or not a certain urban form is sustainable.

- One of the key scientific and intellectual challenges pertaining to sustainable urban forms is to relate the underlying typologies and infrastructures to their operational functioning and planning through control, automation, management, optimization, and enhancement.

- There will always be challenges to address and overcome and hence improvements to realize in the field of sustainable cities, and this has much to do with the perception underlying the conceptualization of progress concerning cities. This centers around what we think we are aspiring to, what we assess "progress" to be, and what changes we want to make. 
embracing what big data computing and the underpinning technologies have to offer in order to bring about sustainable development and thus achieve sustainability under what is labeled "smart sustainable cities of the future." The range of the emerging big data applications as novel analytical and practical solutions that can be utilized for enhancing the sustainability performance of sustainable cities is potentially huge. A recent study conducted by Bibri [13] reveals that tremendous opportunities are available for utilizing big data applications to improve, advance, and maintain the contribution of sustainable cities to the goals of sustainable development. This finding is based on identifying, synthesizing, distilling, and enumerating the most common big data applications in relation to a number of urban domains or sub-domains, as well as elucidating their sustainability effects associated with the underlying functionalities pertaining to these domains or sub-domains. These specifically include transport and traffic, mobility, energy, power grid, environment, buildings, infrastructures, urban planning, urban design, governance, healthcare, education, public safety, and academic and scientific research.

The potential of big data technology lies in enabling sustainable cities to harness and leverage their informational landscape in effectively understanding, monitoring, probing, and planning their systems in ways that enable them to achieve the optimal level of sustainability. To put it differently, the use of this advanced technology is projected to play a significant role in realizing the key characteristic features of such cities, namely the efficiency of operations and functions, the efficient utilization of natural resources, the intelligent management of infrastructures and facilities, the lowering of pollution and waste, the improvement of the quality of life and well-being of citizens, and the enhancement of mobility and accessibility.

\section{Discussion and conclusion}

Long-lasting and substantive transformations such as sustainability transitions can only come about through the accumulation of several integrated smaller-scale actions associated with strategically successful initiatives and programs. The backcasting approach to futures studies can help to highlight such initiatives and programs, and also play a key role in sustaining the momentum in the quest to bring about major transformations. In the context of city planning and development, this approach can be used to illustrate what might happen to cities in order to allow them to adapt to perceived future trends and to manage uncertainty. As such, it aids in dealing with this uncertainty by clarifying what the most desirable possibilities are, what can be known, what is already known, as well as how today's decisions may play out in each of a variety of plausible futures. Futures studies using backcasting approaches allow for a better understanding of future opportunities and exploring the implications of alternative development paths that can be relied on to avoid the impacts of the future. There is a strong belief that future-orientated planning can change development paths. The interest in the future of smart sustainable cities is driven by the aspiration to transform the continued urban development path. Therefore, it is worthy to venture some thoughts about where it might be useful to channel the efforts now and in the future in relation to smart sustainable urban planning and development. The backcasting scenario, a description of possible actions in the future, starts with constructing the vision of the future and then works backwards in time step-by-step to figure out how this future could emerge as a particular "desired end-point" through identifying the necessary steps to reach it.

This paper aimed to generate a vision for smart sustainable cities of the future by answering the 6 guiding questions for step 3 of the futures study being conducted. We described the terms of reference for the future vision under the visionary approach. These terms entail the scope and limitation of the area of knowledge to be focused on and the description of the structure and objectives of the futures study. Then, we described how the future vision look like, more specifically, the novel model for smart sustainable cities of the future and its role in achieving the optimal level of sustainability. Following this, we detailed how the proposed model is different from existing approaches to urbanism, namely compact cities, eco-cities, data-driven smart cities by describing and discussing the three strands that comprise this model, as well as how they intertwine with one another in the context of sustainability. This was justified by providing the rationale for developing the future vision, which represents the short and concise version of the respective model. Of particular importance, we provided a tabulation version of the review and discussion of the sustainability problems and issues that are supposed to be tackled by meeting the objectives stated and thus achieving the goals specified in step 1 of the backcasting study. In relation to this, we provided an account of the kind of technologies and their novel applications that are intended to be used as part of the proposed model.

Working with a long-term image of the future is meant to increase the possibilities of, and accelerate the movement towards, reaching a smart sustainable city. In this regard, the novel model for smart sustainable cities of the future will be the boost to new forms of policy analysis and planning in the era of big data revolution, and the greatest impacts of big data technology will be on the way we improve, advance, and maintain the contribution of sustainable cities to the goals of sustainable development in the future by means of integrating urban 
strategies and technological innovations. The main goal of big data technology is to provide intelligence functions that will make this possible in the most effective ways.

Worth pointing out is that smart sustainable cities as an integrated model take multiple forms of combining the strengths of sustainable cities and smart cities based on how the concept of smart sustainable cities can be conceptualized and operationalized. Just as it has been the case for sustainable cities: there are multiple visions of, and pathways towards achieving, sustainable urban development. As a corollary of this, there is a host of unexplored opportunities towards new approaches to smart sustainable urban planning and development. These future endeavors reflect the characteristic spirit and prevailing tendency of the ICT-sustainability-urbanization era as manifested in its aspirations for directing the advances in ICT of pervasive computing towards addressing and overcoming the challenges of sustainability and urbanization in the defining context of smart sustainable cities of the future.

Similarly, in relation to backcasting as a planning approach, multiple visions can be used to explore different future alternatives as to smart sustainable cities. It is important, though, to take into consideration that big data technologies as part of future visions seem to be deurbanized in the sense of not being made to work within a particular urban context, or to be tailored to different urban landscapes and strategies. Besides, it is unfeasible simply to plop down advanced technologies and force them to work in a given urban space. Cities are so characterized by key specificities such that technology systems might work in one city and not be desirable in another, unless they are dramatically reworked or reshaped to be practical in those cities where they have to be implemented. Hence, there is a need for urbanizing big data technologies and in different directions, we content and advocate, when it comes to generating future visions. With that in mind, the future vision this paper is concerned with pertains to cities in ecologically and technologically advanced nations.

\section{Acknowledgements}

Not applicable

\section{Authors' contributions}

Both authors read and approved the final manuscript.

\section{Author's information}

Simon Elias Bibri is a Ph.D scholar in the area of data-driven smart sustainable cities of the future and Assistant Professor at the Norwegian University of Science and Technology (NTNU), Department of Computer Science and Department of Architecture and Planning, Trondheim, Norway. He holds the following degrees:

1. Bachelor of Science in computer engineering with a major in software development and computer networks
2. Master of Science —-research focused —in computer science with a major in Ambient Intelligence

3. Master of Science in computer science with a major in informatics

4. Master of Science in computer and systems sciences with a major in decision support and risk analysis

5. Master of Science in entrepreneurship and innovation with a major in new venture creation

6. Master of Science in strategic leadership towards sustainability

7. Master of Science in sustainable urban development

8. Master of Science in environmental science with a major in ecotechnology and sustainable development

9. Master of Social Science with a major in business administration (MBA)

10. Master of Arts in communication and media for social change

11. Postgraduate degree (1 year of Master courses) in management and economics

12. $\mathrm{PhD}$ in computer science and urban planning with a major in datadriven smart sustainable cities

Bibri has earned all his Master's degrees from different Swedish universities, namely Lund University, West University, Blekinge Institute of Technology, Malmö University, Stockholm University, and Mid-Sweden University. His current research interests include smart sustainable cities, sustainable cities, smart cities, urban science, urban analytics, sustainability science, complexity science, data-intensive science, data-driven and scientific urbanism, as well as big data computing and its core enabling and driving technologies, namely sensor technologies, data processing platforms, big data applications, cloud and fog computing infrastructures, and wireless communication networks.

Bibri has authored four academic books whose titles are as follows:

1. The Human Face of Ambient Intelligence: Cognitive, Emotional, Affective, Behavioral and Conversational Aspects (525 pages), Springer, 07/2015.

2. The Shaping of Ambient Intelligence and the Internet of Things: Historico-epistemic, Socio-cultural, Politico-institutional and Ecoenvironmental Dimensions (301 pages), Springer, 11/2015.

3. Smart Sustainable Cities of the Future: The Untapped Potential of Big Data Analytics and Context-Aware Computing for Advancing Sustainability (660 pages), Springer, 03/2018.

4. Big Data Science and Analytics for Smart Sustainable Urbanism: Unprecedented Paradigmatic Shifts and Practical Advancements (505 pages), Springer, 06/2019.

Funding

Not Applicable.

Availability of data and materials

Not applicable

Ethics approval and consent to participate

Not Applicable

Consent for publication

Not Applicable

Competing interests

The authors declare that they have no competing interests.

Received: 14 February 2019 Accepted: 18 July 2019

Published online: 28 August 2019

References

1. Alberti M (2000) Urban form and ecosystem dynamics: empirical evidence and practical implications. In: Williams K, Burton E, Jenks M (eds) Achieving sustainable urban form. E \& FN Spon, London, pp 84-96

2. Al Nuaimi E, Al Neyadi H, Nader M, Al-Jaroodi J (2015) Applications of big data to smart cities. J Internet Serv Appl 6(25):1-15

3. Angelidou M, Psaltoglou A, Komninos N, Kakderi C, Tsarchopoulos P, Panori A (2017) Enhancing sustainable urban development through smart city applications. J Sci Technol Policy Manage:1-25 
4. Batty M, Axhausen KW, Giannotti F, Pozdnoukhov A, Bazzani A, Wachowicz M, Ouzounis G, Portugali Y (2012) Smart cities of the future. Eur Phys J 214:481-518

5. Beatley T (2000) Green urbanism: learning from European cities. Island Press, Washington, DC

6. Bettencourt LMA (2014) The uses of big data in cities. Santa Fe Institute, Santa Fe

7. Bibri SE (2018a) Smart sustainable cities of the future: the untapped potential of big data analytics and context aware computing for advancing sustainability. Springer, Berlin

8. Bibri SE (2018b) The loT for smart sustainable cities of the future: an analytical framework for sensor-based big data applications for environmental sustainability. Sustain Cities and Soc 38:230-253

9. Bibri SE (2018c) A foundational framework for smart sustainable city development: theoretical, disciplinary, and discursive dimensions and their synergies. Sustain Cities Soc 38:758-794

10. Bibri SE (2018d) Backcasting in futures studies: a synthesized scholarly and planning approach to strategic smart sustainable city development. Eur J Future Res:2-27

11. Bibri SE, Krogstie J (2017) The core enabling technologies of big data analytics and context-aware computing for smart sustainable cities: a review and synthesis. J Big Big Data 4(38):1-50

12. Bibri SE (2019a) On the sustainability of smart and smarter cities in the era of big data: an interdisciplinary and transdisciplinary literature review. J Big Data 6(25):2-64

13. Bibri SE (2019b) Big data science and analytics for smart sustainable urbanism: unprecedented paradigmatic shifts and practical advancements. Springer, Germany, Berlin

14. Bibri SE (2019c) The Sciences Underlying Smart Sustainable Urbanism: Unprecedented Paradigmatic and Scholarly Shifts in Light of Big Data Science and Analytics. Smart Cities 2(2):179-213

15. Bibri SE (2019d) The anatomy of the data-driven smart sustainable city: instrumentation, datafication, computerization and related applications. J Big Data 6:59

16. Bibri SE, Krogstie J (2017a) Smart sustainable cities of the future: an extensive interdisciplinary literature review. Sustain Cities Soc 31:183-212

17. Bibri SE, Krogstie J (2017b) ICT of the new wave of computing for sustainable urban forms: their big data and context-aware augmented typologies and design concepts. Sustain Cities Soc 32:449-474

18. Bibri SE, Krogstie J (2018) The big data deluge for transforming the knowledge of smart sustainable cities: a data mining framework for urban analytics, proceedings of the $3 \mathrm{~d}$ annual international conference on smart city applications. ACM, Tetouan

19. Bibri SE, Krogstie J (2019) A Scholarly Backcasting Approach to a Novel Model for Smart Sustainable Cities of the Future: Strategic Problem Orientation, Journal of City, Territory, and Architecture (in press).

20. Bifulco F, Tregua M, Amitrano CC, D'Auria A (2016) ICT and sustainability in smart cities management. Int J Public Sect Manage 29(2):132-147

21. Breheny M (ed) (1992) Sustainable development and urban form. Pion, London

22. Bulkeley H, Betsill M (2005) Rethinking sustainable cities: multilevel governance and the "urban" politics of climate change. Environ Politics 14(1):42-63

23. Carlsson-Kanyama A, Dreborg KH, Eenkhorn BR, Engström R, Falkena B (2003) Image of everyday life in the future sustainable city: experiences of back-casting with stakeholders in five European cities. The Environmental Strategies Research Group (Fms) - report 182, The Royal Institute of Technology, Stockholm, Sweden, 2003. Report available at/react-text

24. CEC (1990) Green paper on the urban environment - communication from the Commission to the Council and the Parliament. Commission of the European Communities (CEC), Brussels

25. Council of Europe (1993) The European urban charter-standing conference of local and regional authorities of Europe.

26. David D (2017) Environment and urbanization. Int Encyclopedia Geogr 24(1):31-46. https://doi.org/10.1002/9781118786352.wbieg0623

27. Dempsey N, Jenks M (2010) The future of the compact city. Built Environ 36(1):116-121

28. De Roo G (2000) Environmental conflicts in compact cities: complexity, decision - making, and policy approaches. Environment and Planning B: Planning and Design 27:151-162
29. Dreborg KH (1996) Essence of backcasting. Futures 28(9):813-828

30. Dryzek JS (2005) The politics of the earth: environmental discourses 2 nd ed. Oxford University Press, Oxford

31. Estevez E, Lopes NV, Janowski T (2016) Smart sustainable cities. Reconnaissance Study 330

32. Frey H (1999) Designing the city: towards a more sustainable urban form. E \& FN Spon, London

33. Graedel T (2011) Industrial ecology and the ecocity. National Academy of engineering

34. Han J, Meng X, Zhou X, Yi B, Liu M, Xiang W-N (2016) A long-term analysis of urbanization process, landscape change, and carbon sources and sinks: a case study in China's Yangtze River Delta region. J Clean Prod 141:10401050. https://doi.org/10.1016/j.jclepro.2016.09.177

35. Harvey F (2011) Green vision: the search for the ideal eco-city. Financ Times London

36. Hollands RG (2008) Will the real smart city please stand up? City Anal Urban Trends Cult Theory Policy Action 12(3):303-320

37. Holmberg J (1998) Backcasting: a natural step in operationalizing sustainable development. Greener Manage Int (GMI) 23:30-51

38. Holmberg J, Robèrt KH (2000) Backcasting from non-overlapping sustainability principles: a framework for strategic planning. Int J Sustain Dev World Ecol 7(4):291-308

39. Höjer M (2000) What is the point of IT? Backcasting urban transport and land-use futures. Doctoral dissertation, Department of Infrastructure and Planning. The Royal Institute of Technology, Stockholm

40. Jabareen YR (2006) Sustainable urban forms: their typologies, models, and concepts. J Plann Educ Res 26:38-52

41. Jenks M, Burton E, Williams K (1996a) A sustainable future through the compact city? Urban intensification in the United Kingdom. Environ Des 1(1):5-20

42. Jenks M, Burton E, Williams K (eds) (1996b) The compact city: a sustainable urban form? E\&FN Spon Press, London

43. Joss S (2010) Eco-cities-a global survey 2009. WIT Trans Ecol Environ 129:239-250

44. Joss S (2011) Eco-cities: the mainstreaming of urban sustainability; key characteristics and driving factors. Int J Sustain Dev Plan 6(3):268-285

45. Joss S, Cowley R, Tomozeiu D (2013) Towards the ubiquitous eco-city: an analysis of the internationalisation of eco-city policy and practice. J Urban Res Pract 76:16-22

46. Kitchin R (2014) The real-time city? Big data and smart urbanism. Geo J 79:1-14

47. Kitchin R (2015) Data-Driven. Networked Urbanism. https://doi.org/10.2139/ ssrn.2641802

48. Kitchin R (2016) The ethics of smart cities and urban science. Phil Trans R Soc A 374:20160115

49. Kramers A, Höjer M, Lövehagen N, Wangel J (2014) Smart sustainable cities: exploring ICT solutions for reduced energy use in cities. Environ Model Softw 56:52-62

50. Kramers A, Wangel J, Höjer M (2016) Governing the smart sustainable city: the case of the Stockholm Royal Seaport. In: Proceedings of ICT for sustainability 2016, vol 46. Atlantis Press, Amsterdam, pp 99-108

51. Kourtit K, Nijkamp P, Arribas-Bel D (2012) Smart cities perspective-a comparative European study by means of self-organizing maps. Innovation 25(2):229-246

52. Miola A (2008) Backcasting approach for sustainable mobility. European Commission, Joint Research Centre, Institute for Environment and Sustainability

53. Neirotti P, De Marco A, Cagliano AC, Mangano G, Scorrano F (2014) Current trends in smart city initiatives-some stylized facts. Cities 38:25-36

54. Neuman M (2005) The compact city fallacy. J Plan Educ Res 25:11-26

55. Newman P (2000) Urban form and environmental performance. In: Williams K, Burton E, Jenks M (eds) Achieving sustainable urban. E \& FN Spon, London, pp 46-53

56. Quist J, Rammelt C, Overschie M, de Werk G (2006) Backcasting for sustainability in engineering education: the case of Delft University of Technology. J Clean Prod 14:868-876

57. Quist J, Knot M, Young W, Green K, Vergragt P (2001) Strategies towards sustainable households using stakeholder workshops and scenarios. Int J Sustain Dev 4:75-89

58. Pantelis K, Aija L (2013) Understanding the value of (big) data. In: Big data 2013 IEEE international conference on IEEE, pp 38-42

59. Phdungsilp A (2011) Futures studies' backcasting method used for strategic sustainable city planning. Futures 43(7):707-714

60. Rapoport E, Vernay AL (2011) Defining the eco-city: a discursive approach In: Paper presented at the management and innovation for a sustainable 
built environment conference, international eco-cities initiative. The Netherlands, Amsterdam, pp 1-15

61. Register R (2002) Eco-cities: building cities in balance with nature. Berkeley Hills Books, Berkeley, CA

62. Rivera MB, Eriksson E, Wangel I (2015) ICT practices in smart sustainable cities-in the intersection of technological solutions and practices of everyday life. In: 29th international conference on informatics for environmental protection (Envirolnfo 2015), third international conference on ICT for sustainability (ICT4S 2015). Atlantis press, The Netherlands, pp 317-324

63. Robinson J, Tinker J (1998) Reconciling ecological, economic and social imperatives. In: Schnurr J, Holtz S (eds) The cornerstone of development: integrating environmental, social, and economic policies. IDRC International Development Research Center and Lewis Publishers, Ottawa, pp 9-43

64. Roseland M (1997) Dimensions of the eco-city. Cities 14(4):197-202

65. Rotmans J et al (2000) Visions for a sustainable Europe. Futures 32(2000):809-831

66. Roth A, Kaberger T (2002) Making transport sustainable. J Clean Prod 10:361-371

67. Sev A (2009) How can the construction industry contribute to sustainable development? A conceptual framework. Sustain Dev 17:161-173

68. Shahrokni H, Årman L, Lazarevic D, Nilsson A, Brandt N (2015) Implementing smart urban metabolism in the Stockholm Royal Seaport: smart city SRS. J Ind Ecol 19(5):917-929

69. Suzuki, H, Dastur, A, Moffatt, S, Yabuki, N, Maruyama, H. (2010) Eco2 cities ecological cities as economic cities. The World Bank

70. Talen E, Ellis C (2002) Beyond relativism: reclaiming the search for good city form. J Plann Edu Res 22:36-49

71. Townsend A (2013) Smart cities_-big data, civic hackers and the quest for a new utopia. Norton \& Company, New York

72. Tuominent P, Tapio T, Jarvi, Banister D (2014) Pluralistic backcasting: Integrating multiple visions with policy packages for transport climate policy. Futures 60:41-58

73. United Nations (2015) Big Data and the 2030 agenda for sustainable development. Prepared by A. Maaroof.

74. Van Bueren E, van Bohemen H, Itard L, Visscher H (2011) Sustainable urban environments: an ecosystem approach. International Publishing, Springer

75. Van U-P, Senior M (2000) The contribution of mixed land uses to sustainable travel in cities. In: Williams K, Burton E, Jenks M (eds) Achieving sustainable urban form. E \& FN Spon, London, pp 139-148

76. Weaver $P$, Jansen $L$, van Grootveld G, van Spiegel E, Vergragt P (2000) Sustainable technology development. Greenleaf Publishers, Sheffield

77. Wheeler SM, Beatley T (eds) (2010) The sustainable urban development reader. Routledge, London, New York

78. Whitehead M (2003) (Re)Analysing the Sustainable City: Nature, Urbanism and the Regulation of Socio-Environmental Relations in the UK. Urban Studies 40(7):1183-1206

79. Williams K (2009) Sustainable cities: research and practice challenges. Int J Urban Sustain Dev 1(1):128-132

80. Williams K, Burton E, Jenks M (eds) (2000) Achieving sustainable urban form. E \& FN Spon, London

81. Yigitcanlar T, Lee SH (2013) Korean ubiquitous-eco-city: a smart-sustainable urban form or a branding hoax? J. Tech For Soc Ch 89:100-114

\section{Publisher's Note}

Springer Nature remains neutral with regard to jurisdictional claims in published maps and institutional affiliations.

\section{Submit your manuscript to a SpringerOpen ${ }^{\circ}$ journal and benefit from:}

- Convenient online submission

- Rigorous peer review

- Open access: articles freely available online

- High visibility within the field

- Retaining the copyright to your article

Submit your next manuscript at $\boldsymbol{\nabla}$ springeropen.com 